OPEN ACCESS

Edited by:

Detlef Neumann,

Hannover Medical School, Germany

Reviewed by:

Anisur Rahman,

University College London, UK

Marco De Andrea,

University of Turin, Italy

*Correspondence:

Panagiotis Antiochos

panagiotis.antiochos@chuv.ch

tThese authors have contributed equally to this work.

Specialty section:

This article was submitted to

Cytokines and Soluble Mediators in Immunity,

a section of the journal

Frontiers in Immunology

Received: 28 January 2017

Accepted: 28 March 2017

Published: 18 April 2017

Citation:

Antiochos P, Marques-Vidal P, Virzi J,

Pagano S, Satta N, Hartley O, Montecucco F, Mach F, Kutalik Z,

Waeber $G$, Vollenweider $P$ and

Vuilleumier N (2017) Anti-

Apolipoprotein A-1 lgG Predict

All-Cause Mortality and Are

Associated with Fc Receptor-Like 3

Polymorphisms.

Front. Immunol. 8:437.

doi: 10.3389/fimmu.2017.00437

\section{Anti-Apolipoprotein A-1 IgG Predict All-Cause Mortality and Are Associated with Fc Receptor-Like 3 Polymorphisms}

\author{
Panagiotis Antiochos ${ }^{1 *}$, Pedro Marques-Vidal', Julien Virzi ${ }^{2,3}$, Sabrina Pagano ${ }^{2,3}$, \\ Nathalie Satta ${ }^{2,3}$, Oliver Hartley ${ }^{4}$, Fabrizio Montecucco ${ }^{2,5,6}$, François Mach $^{5}$, \\ Zoltán Kutalik ${ }^{7,8}$, Gerard Waeber ${ }^{1}$, Peter Vollenweider ${ }^{1 \dagger}$ and Nicolas Vuilleumier ${ }^{2,3+}$ \\ ${ }^{1}$ Department of Internal Medicine, Lausanne University Hospital, Lausanne, Switzerland, ${ }^{2}$ Division of Laboratory Medicine, \\ Department of Genetics and Laboratory Medicine, Geneva University Hospitals, Geneva, Switzerland, ${ }^{3}$ Faculty of Medicine, \\ Department of Human Protein Sciences, University of Geneva, Geneva, Switzerland, ${ }^{4}$ Faculty of Medicine, Department of \\ Pathology and Immunology, University of Geneva, Geneva, Switzerland, ${ }^{5}$ Division of Cardiology, Foundation for Medical \\ Researches, Department of Medical Specialties, University of Geneva, Geneva, Switzerland, ${ }^{6}$ First Clinic of Internal Medicine, \\ Department of Internal Medicine, University of Genoa, Genoa, Italy, ${ }^{7}$ Institute of Social and Preventive Medicine, University \\ Hospital of Lausanne, Lausanne, Switzerland, ${ }^{8}$ Swiss Institute of Bioinformatics, Lausanne, Switzerland
}

Background: Autoantibodies against apolipoprotein A-1 (anti-apoA-1 lgG) have emerged as an independent biomarker for cardiovascular disease and mortality. However, their association with all-cause mortality in the community, as well as their genetic determinants, have not been studied.

Objective: To determine whether anti-apoA-1 lgG: (a) predict all-cause mortality in the general population and (b) are associated with single-nucleotide polymorphisms (SNPS) in a genome-wide association study (GWAS).

Methods: Clinical, biological, and genetic data were obtained from the population-based, prospective CoLaus study, including 5,220 participants (mean age 52.6 years, 47.3\% men) followed over a median duration of 5.6 years. The primary study outcome was all-cause mortality.

Results: After multivariate adjustment, anti-apoA-1 lgG positivity independently predicted all-cause mortality: hazard ratio $(H R)=1.54$, 95\% confidence interval $(95 \%$ $\mathrm{Cl}): 1.11-2.13, P=0.01$. A dose-effect relationship was also observed, each SD of logarithmically transformed anti-apoA-1 IgG being associated with a 15\% increase in mortality risk: $\mathrm{HR}=1.15,95 \% \mathrm{Cl}: 1.02-1.28, P=0.028$. The GWAS yielded nine SNPS belonging to the $\mathrm{Fc}$ receptor-like 3 (FCRL3) gene, which were significantly associated with anti-apoA-1 lgG levels, with the lead SNP ( $r$ 6427397, $P=1.54 \times 10^{-9}$ ) explaining $0.67 \%$ of anti-apoA-1 lgG level variation.

Conclusion: Anti-apoA-1 lgG levels (a) independently predict all-cause mortality in the general population and (b) are linked to FCRL3, a susceptibility gene for numerous autoimmune diseases. Our findings indicate that preclinical autoimmunity to anti-apoA-1 IgG may represent a novel mortality risk factor.

Keywords: autoimmunity, autoantibodies, apolipoprotein A-1, mortality, genome-wide association study, Fc receptor-like 3 


\section{INTRODUCTION}

Autoimmune diseases (ADs) represent a major health issue affecting up to $10 \%$ of the population (1-4). Multiple studies have established the relationship between a chronic inflammatory state due to clinical or quiescent autoimmunity and poor outcomes in various clinical settings $(5,6)$. Marking sustained B-cell activation, presence of autoantibodies specifically represents a signature of humoral autoimmunity, which can drive disease pathogenesis even in the absence of overt clinical AD (7-9).

More than a decade ago, early clinical studies have supported the role of autoantibodies against apolipoprotein A-1 (anti-apoA-1 IgG), the principal component of high-density lipoproteins (HDLs), as mediators of chronic low-grade inflammation and predictors of unfavorable outcomes in patients with ADs (10-17). Subsequently, in vitro and animal studies demonstrated the ability of these autoantibodies to elicit a proinflammatory and pro-atherogenic response through interaction with the TLR2/TLR4/CD14 complex, followed by NF- $\kappa B$ and MAPK downstream activation as the main molecular pathway (18-24).

Recently, due to these pro-inflammatory and pro-atherogenic properties, anti-apoA-1 IgG gained interest as independent biomarkers for incident cardiovascular (CV) disease (CVD) and mortality, as well as potential therapeutic targets for immunemodulating interventions, in high CV risk populations $(16,19$, 20, 22, 25-28). Moreover, similar to what has been reported with other autoantibodies (7), our group recently demonstrated that elevated anti-apoA-1 IgG levels were present in up to $20 \%$ of individuals in the general population and associated with prevalent CVD independently of traditional CV risk factors (25). Nevertheless, the association of anti-apoA-1 IgG with all-cause mortality in the general population has not yet been studied.

From another point of view, while rare autoimmunity syndromes can result from monogenic mutations, common human $\mathrm{ADs}$ are complex disorders arising from the interaction between polygenic and environmental risk factors, disrupting mechanisms of immune tolerance. In recent years, genome-wide association studies (GWASs) have provided insight into the subtle immune dysregulation caused by common genetic variants that predispose to clinical autoimmunity $(29,30)$ and autoantibody production in particular (31-34).

Although the risk attributable to most of the identified individual nucleotide variants is modest, modern GWAS have the potential to provide an unbiased view of biological pathways that drive autoimmunity (1-4). However, despite the associations of anti-apoA-1 IgG with adverse outcomes in different patient populations, no study has so far investigated common genetic variants potentially related to their serum values.

Thus, the goal of the present study was twofold. We aimed to determine whether anti-apoA-1 IgG: (a) predict all-cause mortality in the general population in a prospective study and (b) are associated with single-nucleotide polymorphisms (SNPs) in a GWAS.

\section{METHODS}

\section{Study Population and Design}

Clinical and biological data were obtained from the CoLaus study, a population-based prospective cohort of 6,733 participants recruited between 2003 and 2006 in the city of Lausanne, Switzerland. Of the initial baseline sample of 6,733 participants, 5,220 (mean age $52.6 \pm 10.7$ years, $47.3 \%$ men) had complete clinical and biological data over a median follow-up (FU) time of 5.6 years and were included in the prospective analysis. A detailed description of the study design, variables, and sampling procedures has been reported elsewhere (35).

All participants attended the outpatient clinic of the University Hospital of Lausanne. Clinical data and fasting venous blood samples were collected from each participant by trained field interviewers during a single visit lasting about $60 \mathrm{~min}$. Blood pressure and heart rate were measured three consecutive times using an automated sphygmomanometer (Omron ${ }^{\circledR}$ HEM-907, Matsusaka, Japan), and the average of the last two measurements was used. Body weight and height were measured with participants standing without shoes in light indoor clothes. Body weight was measured in kilograms to the nearest $100 \mathrm{~g}$ using a Seca ${ }^{\circledR}$ scale, and height was measured to the nearest $5 \mathrm{~mm}$ using a Seca ${ }^{\circledR}$ height gauge. Body mass index (BMI) was calculated as weight $(\mathrm{kg}) /$ height $\left(\mathrm{m}^{2}\right)$. Hypertension was defined as a systolic blood pressure $\geq 140 \mathrm{~mm} \mathrm{Hg}$ and/or a diastolic blood pressure $\geq 90 \mathrm{~mm}$ $\mathrm{Hg}$ and/or the presence of anti-hypertensive treatment. Diabetes mellitus was defined as fasting plasma glucose $\geq 7.0 \mathrm{mmol} / \mathrm{l}$ and/ or oral or insulin anti-diabetic treatment. History of CVD was defined by the presence of myocardial infarction, angina pectoris, percutaneous revascularization or bypass grafting for ischemic heart disease, and stroke or transient ischemic attack and assessed according to standardized medical records (35). History of ADs was obtained via questionnaire. Estimated glomerular filtration rate (eGFR) was calculated by the simplified "Modification of Diet in Renal Disease" prediction equation. Absolute risk for CVD was computed using the Systematic Coronary Risk Evaluation algorithm (36).

Venous blood samples were drawn after an overnight fast, and assays were performed on fresh plasma samples within $2 \mathrm{~h}$ of blood collection for standard lipid profile and on unthawed serum aliquots for anti-apoA-1 IgG determination, (see below) that were immediately processed and stored at $-80^{\circ} \mathrm{C}$. Standard lipid profile was performed by the CHUV Clinical Laboratory using a Modular P apparatus (Roche Diagnostics, Switzerland). The following analytical procedures (with maximum inter- and intra-batch CVs) were used: total cholesterol by the "CHODPAP" method (1.6-1.7\%); HDL cholesterol by the "CHOD-PAP/ PEG/Cyclodextrin" method (3.6-0.9\%); triglycerides by the "GPO-PAP" method (2.9-1.5\%); glucose by glucose dehydrogenase $(2.1-1.0 \%)$; and serum creatinine by the Jaffe kinetic compensated method (2.9-0.7\%).

\section{Determination of Anti-apoA-1 IgG Levels}

Autoantibodies against apolipoprotein A-1 were measured as previously described $(19,22,37)$, using the CoLaus study 
(2003-2006) frozen serum aliquots, stored at $-80^{\circ} \mathrm{C}$. Maxisorp plates (Nunc ${ }^{\mathrm{TM}}$, Denmark) were coated with purified, humanderived delipidated apolipoprotein A-1 $(20 \mu \mathrm{g} / \mathrm{ml} ; 50 \mu \mathrm{l} /$ well $)$ for $1 \mathrm{~h}$ at $37^{\circ} \mathrm{C}$. After being washed, all wells were blocked for $1 \mathrm{~h}$ with $2 \%$ bovine serum albumin (BSA) in a phosphate buffer solution (PBS) at $37^{\circ} \mathrm{C}$. Participants' samples were also added to a non-coated well to assess individual non-specific binding. After six washing cycles, a $50 \mu \mathrm{l} /$ well of signal antibody (alkaline phosphatase-conjugated anti-human IgG; Sigma-Aldrich, St. Louis, MO, USA), diluted 1:1,000 in a PBS/BSA 2\% solution, was added and incubated for $1 \mathrm{~h}$ at $37^{\circ} \mathrm{C}$. After washing six more times, phosphatase substrate p-nitrophenyl phosphate disodium (Sigma-Aldrich) dissolved in a diethanolamine buffer ( $\mathrm{pH}$ 9.8) was added and incubated for $20 \mathrm{~min}$ at $37^{\circ} \mathrm{C}$ (Molecular Devices ${ }^{\mathrm{TM}}$ Versa Max). Optical density (OD) was determined at $405 \mathrm{~nm}$, and each sample was tested in duplicate. Corresponding non-specific binding was subtracted from mean OD for each sample. The specificity of detection was assessed using conventional saturation tests by Western blot analysis.

As previously described $(19,22,37)$, elevated levels of antiapoA-1 IgG were set at an OD cut-off of OD $>0.64$, corresponding to the 97.5th percentile of a reference population of 140 healthy blood donors. In order to limit the impact of inter-assay variation, we further calculated an index consisting in the ratio between sample net absorbance and the positive control net absorbance $\times 100$. The index value corresponding to the 97.5th percentile of the normal distribution was 37. Accordingly, to be considered as positive (presenting elevated anti-apoA-1 IgG levels), samples had to display both an absorbance value $>0.64$ OD and an index value $\geq 37 \%$.

\section{Genome-Wide Association Study}

Genotyping was performed using the Affymetrix GeneChip ${ }^{\circledR}$ Human Mapping $500 \mathrm{~K}$ array set and genotypes were called using BRLMM. SNPs with a call rate $<70 \%$ and individuals with call rate $<90 \%$ were excluded from further analysis. Participants found to be of non-European ancestry by principal component analysis of the genotype data were also excluded, leaving 5,402 participants eligible for GWAS. Imputation was performed using IMPUTE version 0.2.0 and CEU haplotypes from HapMap release 21 . The dataset used for imputation consisted in 390,631 genotyped SNPs with a call rate $>0.9$, Hardy-Weinberg $P$-value $>10^{-7}$, and $\mathrm{MAF}>1 \%$.

Before performing the GWAS, anti-apoA-1 IgG levels were adjusted for age, sex, and ancestry principal components. The residuals were then inverse normal quantile transformed and regressed onto genetic allele dosages. To fine map the genomewide significant association at the FCRL2/3 locus, we re-imputed the 400-kb window around the top HapMap-associated SNP using haplotypes from the HRC reference panel.

\section{Study Endpoints}

The primary study endpoint was overall mortality, but specific causes of death were also considered. All deaths and related causes were adjudicated by an independent panel of internal medicine physicians, blinded to all study variables.

\section{Statistics}

Statistical analyses were conducted using Stata v14.1 (Stata Corp., TX, USA) and MatLab v8.3 (MathWorks, MA, USA). Bivariate analysis of continuous variables was performed using Student's or Mann-Whitney test as appropriate, while analysis of categorical variables was performed using chisquare test. The association of anti-apoA-1 IgG levels with all-cause mortality was assessed by the log-rank test and by Cox proportional hazards regression, adjusting for age, gender, hypertension, diabetes, smoking, BMI, eGFR, HDL and lowdensity lipoprotein (LDL) cholesterol, baseline CVD, and AD. Anti-apoA-1 IgG concentrations were natural log transformed to account for skewed distributions, and results were expressed as hazard ratios (HRs) and 95\% confidence intervals (95\% CIs). Considering a two-sided alpha of 0.05 , our study had $80 \%$ power to detect a relative risk for all-cause mortality of 1.45 in participants positive for anti-apoA-1 IgG. All tests were two tailed, and $P$ values $<0.05$ were considered as statistically significant.

\section{RESULTS}

Figure 1A shows the participants' selection procedure, and Table S1 in Supplementary Material summarizes the baseline characteristics of participants, with or without FU data. Overall, subjects lost at FU were more likely to be smokers, hypertensive, obese, and with a less favorable lipid profile than subjects included in the analysis, but did not differ with regards to anti-apoA-1 IgG positivity or serum levels.

During FU, 191 deaths (3.7\%) occurred. The three major causes of death were cancer, CVD, and infectious diseases. Participants who died presented with a significantly higher prevalence of anti-apoA-1 IgG positivity (26.7 vs. $19.6 \%, P=0.016)$ and higher anti-apoA-1 IgG levels (median [interquartile range]: 0.43 $[0.30-0.70]$ vs. $0.39[0.25-0.59] \mathrm{AU}, P=0.007)$, than participants alive at FU (Table 1). Of note, median anti-apoA-1 IgG values of anti-apoA-1 IgG-positive subjects who died at FU were 0.89 [0.79-1.05] AU.

Kaplan-Meier curves for participants with positive and negative anti-apoA-1 IgG titers are shown in Figure 1B; participants positive for anti-apoA-1 IgG had higher mortality rates than participants negative for the marker (4.9 vs. 3.4\%, log-rank $P=0.034)$. Conversely, $95.1 \%$ of anti-apoA-1 IgG-positive subjects survived, compared to $96.6 \%$ of anti-apoA-1 IgG-negative subjects corresponding to an absolute survival difference of $1.5 \%$ between the two groups.

Cox regression analysis indicated that anti-apoA-1 IgG positivity was associated with a 1.5 -fold increased risk of death, and this hazard rate remained unchanged after adjustment for the aforementioned mortality risk factors, including baseline CVD and $\mathrm{AD}: \mathrm{HR}=1.54(1.11-2.13), P=0.01$. Similarly, $1 \mathrm{SD}$ increase of the log-transformed anti-apoA-1 IgG levels was associated with a $15 \%$ increase in the risk of all-cause mortality: $\mathrm{HR}=1.15$ (1.02-1.28), $P=0.028$ (Table 2). Sensitivity analyses excluding participants with CVD or AD at baseline led to comparable findings (Table 2). 
A

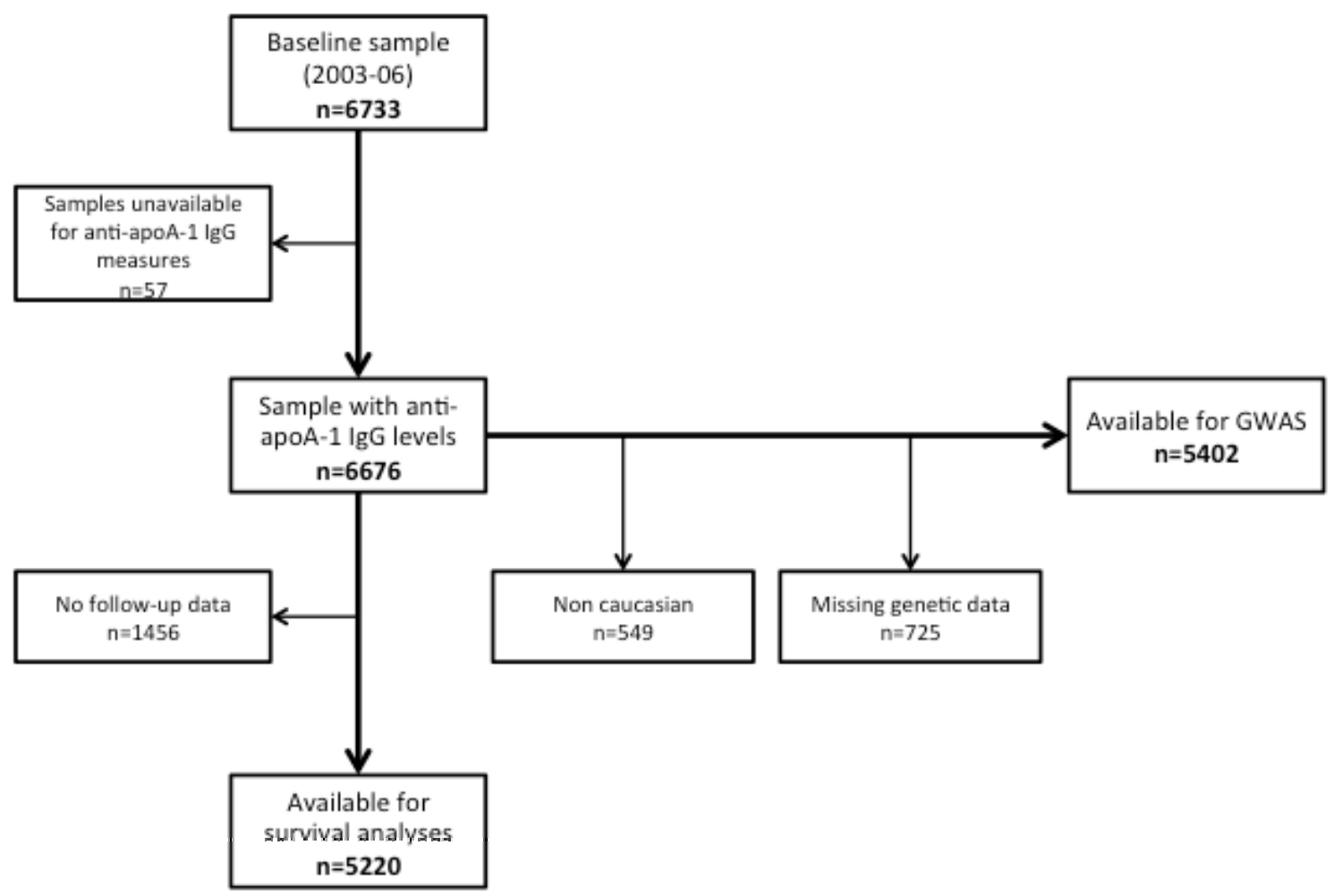

B

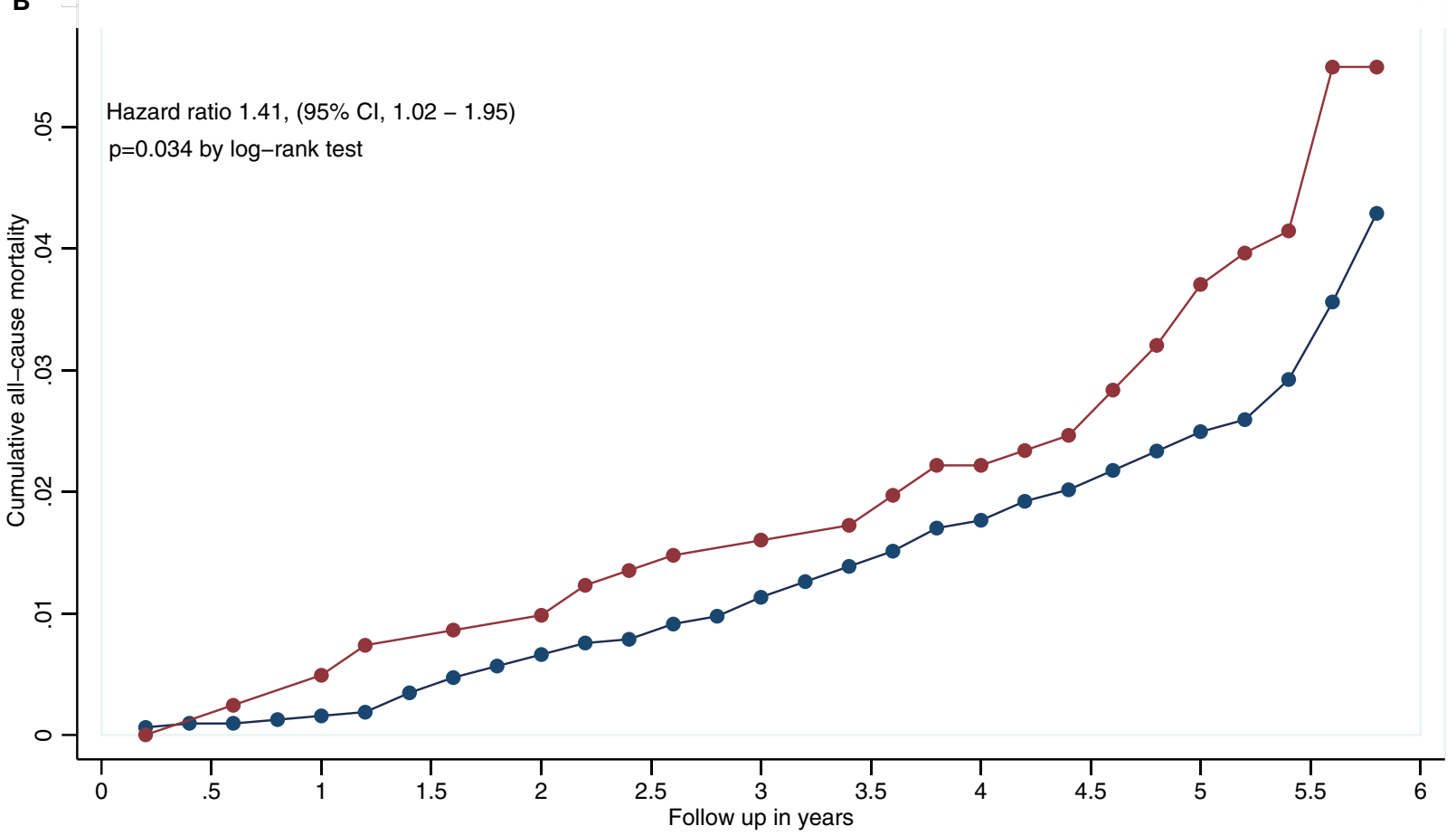

Low anti-apoA-1 IgG levels

High anti-apoA-1 IgG levels

FIGURE 1 | (A) Participants' selection procedure. (B) Kaplan-Meier curves for all-cause mortality, according to autoantibodies against apolipoprotein A-1 (anti-apoA-1 lgG) status. $P$-value according to log-rank test $(P=0.034$ ). 
TABLE 1 | Baseline characteristics of the sample according to all-cause mortality during follow-up.

\begin{tabular}{|c|c|c|c|c|}
\hline & $\begin{array}{c}\text { Overall } \\
(n=5,220)\end{array}$ & $\begin{array}{l}\text { Survivors } \\
(n=5,029)\end{array}$ & $\begin{array}{c}\text { Non- } \\
\text { survivors } \\
(n=191)\end{array}$ & $P$-value \\
\hline Age, years & $52.6 \pm 10.7$ & $52.2 \pm 10.6$ & $62.7 \pm 9.5$ & $<0.001$ \\
\hline Male sex, $n(\%)$ & 2,461 (47.3) & 2,337 (46.6) & $124(64.9)$ & $<0.001$ \\
\hline History of CVD, $n(\%)$ & $379(7.3)$ & $337(6.7)$ & $42(22.0)$ & $<0.001$ \\
\hline Current smoking, $n$ (\%) & $1,356(26.1)$ & $1,277(25.5)$ & $79(41.4)$ & $<0.001$ \\
\hline Diabetes, $n(\%)$ & $326(6.3)$ & $282(5.6)$ & $44(23.0)$ & $<0.001$ \\
\hline $\mathrm{BMl}\left(\mathrm{kg} / \mathrm{m}^{2}\right)$ & $25.6 \pm 4.4$ & $25.6 \pm 4.4$ & $26.7 \pm 5.5$ & $<0.001$ \\
\hline Hypertension, $n$ (\%) & $1,723(33.1)$ & $1,613(32.2)$ & $110(57.6)$ & $<0.001$ \\
\hline $\mathrm{SBP}(\mathrm{mmHg})$ & $127.6 \pm 17.7$ & $127.2 \pm 17.6$ & $135.3 \pm 19.1$ & $<0.001$ \\
\hline eGFR $\left(\mathrm{ml} / \mathrm{min} / 1.73 \mathrm{~m}^{2}\right)$ & $78.7 \pm 15.7$ & $78.8 \pm 15.5$ & $75.4 \pm 20.0$ & 0.014 \\
\hline $\begin{array}{l}\text { Total cholesterol } \\
(\mathrm{mmol} / \mathrm{l})\end{array}$ & $5.56 \pm 1.02$ & $5.57 \pm 1.01$ & $5.53 \pm 1.19$ & 0.625 \\
\hline $\begin{array}{l}\text { HDL cholesterol } \\
(\mathrm{mmol} / \mathrm{l})\end{array}$ & $1.64 \pm 0.44$ & $1.64 \pm 0.44$ & $1.54 \pm 0.47$ & 0.001 \\
\hline LDL cholesterol (mmol/l) & $3.32 \pm 0.91$ & $3.32 \pm 0.90$ & $3.26 \pm 1.02$ & 0.362 \\
\hline Triglycerides (mmol/l) & $1.37 \pm 1.14$ & $1.36 \pm 1.06$ & $1.78 \pm 2.33$ & $<0.001$ \\
\hline SCORE risk (\%) & $2.08 \pm 3.57$ & $1.91 \pm 3.35$ & $6.01 \pm 5.80$ & $<0.001$ \\
\hline Known AD (RA, SLE) & $115(2.2)$ & $110(2.2)$ & $5(2.6)$ & 0.696 \\
\hline $\begin{array}{l}\text { Anti-apoA-1 lgG } \\
\text { positivity }\end{array}$ & 1,035 (19.9) & 984 (19.6) & $51(26.7)$ & 0.016 \\
\hline $\begin{array}{l}\text { Anti-apoA-1 lgG levels } \\
(\mathrm{AU})\end{array}$ & 0.39 [0.34] & 0.39 [0.33] & $0.43[0.40]$ & 0.007 \\
\hline $\begin{array}{l}\text { Incident overall death } \\
\text { rate, } n(\%)\end{array}$ & $191(3.7)$ & & $191(3.7)$ & \\
\hline Cancer-related, $n$ (\%) & $69(36.1)$ & & $69(36.1)$ & \\
\hline CVD-related, $n(\%)$ & $36(18.9)$ & & 36 (18.9) & \\
\hline Infectious-related, $n$ (\%) & $25(13.1)$ & & $25(13.1)$ & \\
\hline Other causes ${ }^{\mathrm{a}}, n(\%)$ & $51(26.7)$ & & $51(26.7)$ & \\
\hline Undetermined, $n$ (\%) & $10(5.2)$ & & $10(5.2)$ & \\
\hline
\end{tabular}

$P$ values are derived from the comparison of patients with low vs. high levels of anti-apoA-1 lgG. Variables are expressed as mean \pm SD or median [interquartile range] as appropriate or number of participants and percentage. Statistical analysis for continuous variables was performed by Student's t-test or Mann-Whitney test depending on the normality assumption. Chi-squared test was used for categorical variables.

$A D$, autoimmune disease; $C V D$, cardiovascular disease; SBP, systolic blood pressure; eGFR, estimated glomerular filtration rate according to the MDRD formula; HDL, high-density lipoprotein; $L D L$, low-density lipoprotein; $R A$, rheumatoid arthritis; SLE, systemic lupus erythematosus; SCORE, Systematic Coronary Risk Evaluation; $A U$, arbitrary units of optical density; BMI, body mass index; anti-apoA-1 lgG, autoantibodies against apolipoprotein A-1.

a Other causes include lung disease $(n=12)$, bleeding and trauma-related complications $(n=11)$, suicide $(n=9)$, chronic renal failure $(n=6)$, non-ischemic heart failure $(n=5)$, chronic liver failure $(n=5)$, and dementia $(n=3)$.

Genome-wide association study on anti-apoA-1 IgG levels identified a single locus located in chromosome 1 (157.6$157.9 \mathrm{Mb}$ ) including $21 \mathrm{SNPs}$ significantly associated with anti-apoA-1 IgG levels (Figure 2A; Table S2 in Supplementary Material). The T allele of the lead SNP (rs6427397) was associated with an increase of anti-apoA-1 IgG levels by $0.113 \mathrm{AU}$ and explained $0.67 \%$ of anti-apoA-1 IgG variation. Conversely, in logistic regression (yes vs. no anti-apoA-1 IgG positivity) analysis, the T allele of rs6427397 had an odds ratio (OR) of 1.27 (95\% CI 1.15-1.40) for anti-apoA-1 IgG positivity in our sample. The 20 remaining SNPs identified in the same region were in strong linkage disequilibrium and associated with anti-apoA-1 levels at $P$-value $<10^{-7}$ (Figure 2B). Most of these SNPs were located in or near the $\mathrm{Fc}$ receptor-like 2 (FCRL2) and 3 (FCRL3) genes and to some extend in the regions spanning the FCRL1 gene (Figures 2B,C). SNPs with a previously known biological function or association with a clinical trait were located in the FCRL3 gene (Table S2 in Supplementary Material). Additionally, the only coding polymorphism among the identified SNPs represents a missense variant (rs7522061) also located in the FCRL3 gene. We also observed an association between anti-apoA-1 IgG and a missense variant (rs1047989) in the human leukocyte antigen (HLA)-DQA1 gene, which did not, however, achieve stringent genome-wide significance $\left(P=7.27 \times 10^{-7}\right.$, data not shown).

\section{DISCUSSION}

This is the first study to demonstrate that anti-apoA-1 IgG levels are significantly and independently associated with all-cause mortality in the general population. In our population, after 5 years of FU, $95.1 \%$ of anti-apoA-1-positive subjects survived, compared to $96.6 \%$ of anti-apoA-1-negative participants. This corresponds to a modest, nevertheless, significant $(P=0.03)$ absolute survival difference of $1.5 \%$ between the two groups.

Our results extend previous findings $(19,22,25,26)$ and suggest that preclinical autoimmunity against apoA-1/HDL-which affects up to one-fifth of the general population-may identify individuals at increased risk of death. Our findings raise the possibility that presence of anti-apoA-1 IgG leads to pathophysiological events affecting not only CV prognosis, but also survival in the long term. Based upon previous studies, such events could be related to a chronic low-grade inflammatory state through sustained activation of the TLR2/TLR4/CD14 complex and production of pro-inflammatory cytokines $(14,18,21,24,38)$, associations with elevated high-sensitivity $\mathrm{C}$-reactive protein and uric acid levels $(23,25)$, impairment of HDL function $(10-13,16$, $17)$, interference with basal heart rate regulation $(22,24,25)$ or B-cell epitope spreading (39). Other pathophysiological mechanisms, other than those currently ascribed to anti-apoA-1 IgG could also be involved, in the same way that multiple molecular pathways underlie the associations of other autoantibodies with all-cause mortality in the community $(7,9,40,41)$. These challenging points will have to be investigated in future clinical and translational research efforts.

The second notable finding of our study is that anti-apoA-1 IgG levels are related to genetic polymorphisms belonging or regulating the FCRL3 gene. Indeed, our lead SNP (rs6427397) is an intergenic variant that represents a strong expression quantitative trait loci for the FCRL3 gene in whole blood $\left(1.2 \times 10^{-12}\right)$ (42). Additionally, among the 20 remaining FCRL SNPs achieving genome-wide significance, the only coding variant identified (rs7522061) is a missense variant of the FCRL3 gene.

$\mathrm{Fc}$ receptor-like genes are located in the human chromosome regions 1q21-23 and belong to the immunoglobulin genes superfamily. FCRL3 in particular is known to encode a mature B-cells co-receptor primarily expressed in secondary lymphoid organs and involved in B cell maturation, regulation, and production of autoantibodies (43-45). Previous work suggests that FCRL3 expression further affects $\mathrm{T}$ regulatory cells development and function, with high expression resulting in abnormal immune activation and breakdown of self-tolerance (46). Corroborating 


\begin{tabular}{|c|c|c|c|c|c|}
\hline & Events (n) & $\begin{array}{c}\text { Unadjusted HR } \\
\text { HR }(95 \% \mathrm{Cl})\end{array}$ & $P$-value & $\begin{array}{l}\text { Adjusted HR }{ }^{a} \\
\text { HR }(95 \% \mathrm{Cl})\end{array}$ & $P$-value \\
\hline \multicolumn{6}{|l|}{ Overall sample $(n=5,220)$} \\
\hline - High vs. low levels & 191 & $1.41(1.02-1.95)$ & 0.035 & $1.54(1.11-2.13)$ & 0.010 \\
\hline - For 1 SD increase in log (anti-apoA-1 lgG) & 191 & $1.14(1.01-1.28)$ & 0.040 & $1.15(1.02-1.30)$ & 0.028 \\
\hline \multicolumn{6}{|l|}{ Participants without CVD at baseline $(n=4,825)$} \\
\hline - High vs. low levels & 149 & $1.42(0.98-2.04)$ & 0.062 & $1.62(1.12-2.34)$ & 0.011 \\
\hline - For 1 SD increase in log (anti-apoA-1 lgG) & 149 & $1.14(0.99-1.31)$ & 0.062 & $1.19(1.03-1.38)$ & 0.019 \\
\hline \multicolumn{6}{|l|}{ Participants without AD at baseline $(n=5,105)$} \\
\hline - High vs. low levels & 186 & $1.42(1.02-1.97)$ & 0.036 & $1.68(1.21-2.34)$ & 0.002 \\
\hline - For 1 SD increase in log (anti-apoA-1 lgG) & 186 & $1.15(1.01-1.30)$ & 0.030 & $1.23(1.07-1.40)$ & 0.002 \\
\hline
\end{tabular}

Data are expressed as adjusted HRs and 95\% Cl. Statistical analysis by Cox proportional hazards regression.

AD, autoimmune disease; HR, hazard ratio; CVD, cardiovascular disease; 95\% Cl, 95\% confidence interval; anti-apoA-1 lgG, autoantibodies against apolipoprotein A-1.

${ }^{a}$ Adjusted for age, sex, hypertension, diabetes, smoking, high- and low-density lipoprotein cholesterol, body mass index, estimated glomerular filtration rate baseline CVD and AD.

these in vivo findings, large-scale GWAS have identified FCRL3related SNPs as major susceptibility genes for numerous ADs in humans $(44,47,48)$.

The observed association of FRCL3 with anti-apoA-1 IgG values in our sample is in line with previous studies showing that two-thirds of candidate loci for autoimmunity discovered by GWAS represent shared risk factors for multiple $\mathrm{ADs}(1,3,49)$. Among potential pathophysiological mechanisms, FCRL3 may predispose to clinical autoimmunity by pleiotropic regulation of the production of other deleterious autoantibodies. FCRL 3 has been associated with the production of cyclic citrullinated peptide autoantibodies in rheumatoid arthritis (RA) (47) and antibodies to thyroid peroxidase in patients suffering from Graves' disease (33). In a study of genetic determinants of autoantibody production in over 8,000 type 1 diabetes cases, Plagnol et al. (31) identified the FCRL3 locus to be associated with antibodies against insulinoma-associated antigen 2 concluding that FCRL 3 "may have general effects in adaptive immunity, in the complex interactions between antigen presenting cells and $\mathrm{T}$ cells leading to antibody producing plasma B cells." Unfortunately, we were unable to measure in our sample other antibodies, such as anti-oxidized LDL, antiphospholipid, antinuclear, or anti-heat shock protein antibodies in order to test this hypothesis.

Finally, with regards to anti-apoA-1 IgG and CV disease and mortality $(19,20,22), F C R L 3$ mRNA levels have been reported to be downregulated in patients with myocardial infarction when compared to those with stable angina or healthy subjects (50), suggesting that FCRL3-mediated immune dysregulation may also be involved in atheromatous plaque instability and rupture.

Although statistically significant, the effect of the $\mathrm{T}$ allele of the lead SNP (rs6427397) on autoantibody levels was modest [OR 1.27 (95\% CI 1.15-1.40)] and explained $0.67 \%$ of total antiapoA-1 IgG variation. This is not surprising since incremental effect sizes of genetic variants are rather common in genetic studies of autoimmunity where most risk alleles have ORs less than $1.2(29,30,32)$ in spite of their low performance regarding disease prediction, these risk variants may provide important etiological information based on associated genomic regions, that could lead to a more sophisticated understanding of the molecular pathways underlying common ADs. Thus, genetic signatures of susceptibility to autoimmunity could provide a basis for assessing heterogeneity in disease progression, in response to targeted immune-modulating interventions, as well as for rational novel drug design.

The fact that the lead SNP in our study relates to an intergenic non-coding variant in the FCRL3 locus is in accordance with current evidence from high-density genotyping and epigenomic studies which demonstrate that in common ADs, up to $90 \%$ of identified causal variants appear to be non-coding, while $60 \%$ correspond to immune cell enhancers (3). The current paradigm supports the notion that intergenic regions are densely populated with hundreds of thousands of regulatory elements that modulate cell type-specific gene expression $(1,3)$. In a study on RA (47), Kochi et al. demonstrated that non-coding SNPs in the promoter region of FCRL3 have a regulatory effect on expression of the FCRL3 gene and relate to augmented autoantibody production in subjects with the susceptible genotype. In the same line of thought, our present results indicate that the sequence of events leading to high of anti-apoA-1 IgG levels could be related to an impaired regulation of gene expression programs-including FCRL3-a hypothesis that requires further study.

Finally, although we did not retrieve any strictly genome-wide significant association between anti-apoA-1 IgG and HLA-related genes, we did observe an association trend at $P=7.27 \times 10^{-7}$ that may represent a clinically meaningful signal in future studies and further relates the presence of these autoantibodies to autoimmunity susceptibility genes.

Study limitations are worth noting. First, our genetic analysis was conducted in a single population sample, including only individuals of Caucasian ancestry and will require further validation in independent cohorts, ideally involving other ethnic groups. Since genetic data on anti-apoA-1 IgG are so far inexistent, we were unable to identify a replication cohort for our GWAS. Nevertheless, our findings represent the first attempt to identify the genetic determinants of anti-apoA-1 IgG. Second, as the specific functionality of T allele of rs6427397 is currently unknown, we can only so far extrapolate on the pathophysiological 


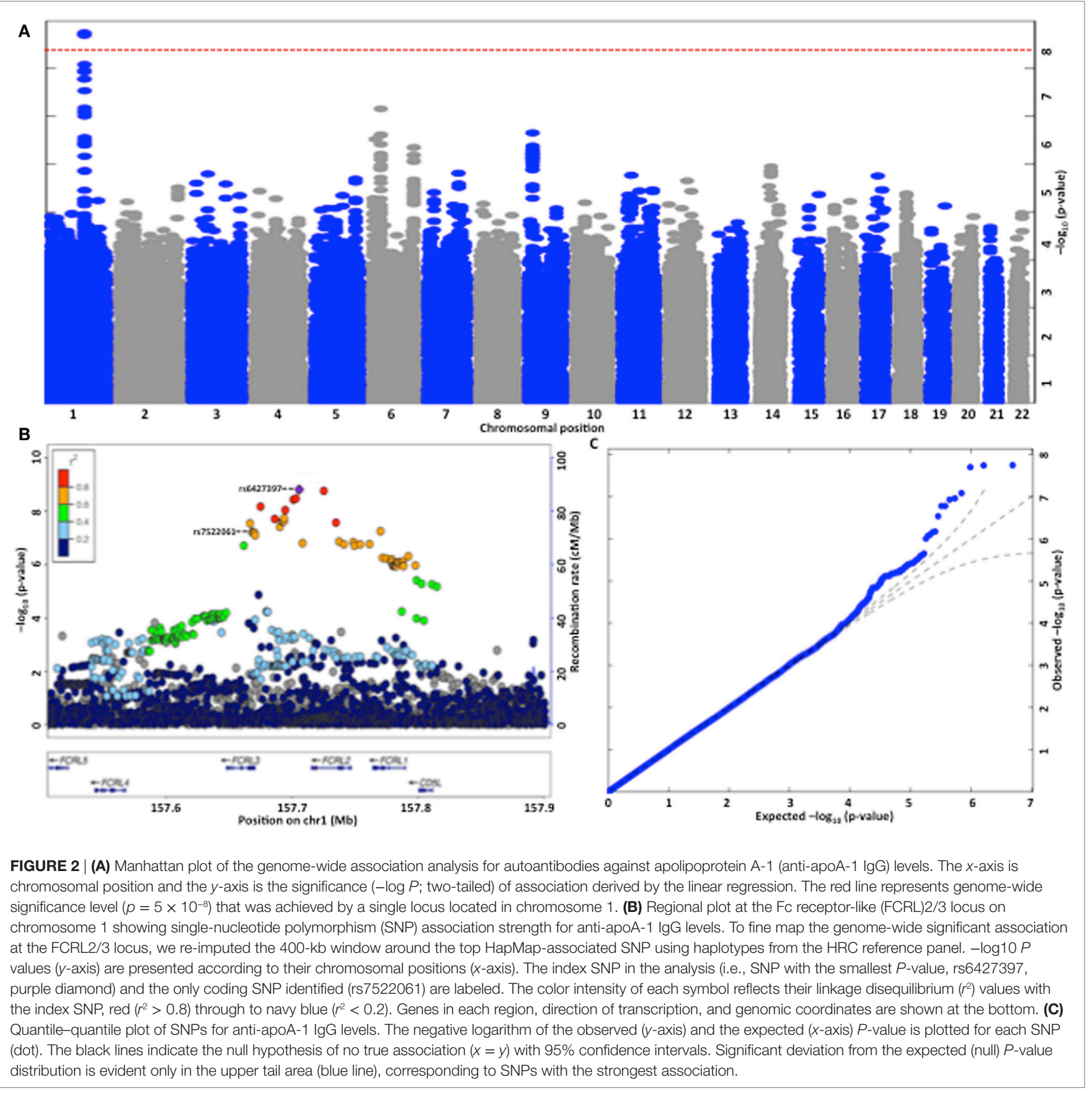

relevance of the reported association, as related to regulation of the FCRL3 gene. Indeed, the only genome-wide significant coding variant identified (rs7522061) is a missense variant of the FCRL3 gene. As we only measured baseline anti-apoA-1 IgG levels, we were not able to assess the dynamic of anti-apoA-1 IgG levels over time in relation with mortality. Knowing whether an increase of anti-apoA-1 IgG would precede clinical events or whether our findings could be affected by transient anti-apoA-1 IgG positivity in a single sample will be important to determine in future studies.
Similarly, one could argue that since the actual difference in anti-apoA-1 IgG levels between the survivors and non-survivors was modest, these results are unlikely to be clinically relevant even though the relative observed difference in anti-apoA-1 IgG values is $9.3 \%$ and statistically significant in our sample $(P=0.007)$, as expected from sample power calculation. The fact that the distribution of anti-apoA-1 IgG values is positively skewed (25) and that low $\mathrm{CV}$ risk participants are known to present lower levels of anti-apoA-1 IgG than high CV risk subjects (19, 22, 25 ) could explain these relatively low anti-apoA-1 IgG values in 
the general population, despite significant differences between survivors and non-survivors. Finally, the observed anti-apoA-1 IgG values translates in a $19.9 \%$ anti-apoA-1 IgG positivity in the sample, which is similar to the reported prevalence of other IgG autoantibodies in the community (7).

Despite these limitations, our study provides-to our best knowledge-the first evidence of a significant association of anti-apoA-1 IgG with all-cause mortality and a major $\mathrm{AD}$ susceptibility gene. Although our findings are in accordance and extending previous results, they will need to be replicated in independent, adequately powered, prospective cohorts before any conclusion on potential clinical implications can be drawn.

\section{CONCLUSION}

Our study suggests that anti-apoA-1 IgG levels predict all-cause mortality in the general population and are associated with a single locus involving FCRL3, a gene known to predispose for ADs. Our findings indicate that preclinical autoimmunity to apoA-1 may identify a substantial proportion of individuals at increased risk of death in the general population, a finding that will need further validation in independent, prospective cohorts.

\section{ETHICS STATEMENT}

The study was approved by the Institutional Ethics Committee of the University of Lausanne, and written informed consent was obtained from all participants before inclusion in the study, in accordance with the Declaration of Helsinki.

\section{AUTHOR CONTRIBUTIONS}

$\mathrm{PA}$ and PM-V contributed in study concept and design, analysis, and interpretation of data, statistical analysis and drafting of the manuscript, and critical revision of the manuscript for important intellectual content. JV, SP, NS, OH, and FM contributed in study concept and design, acquisition of the data, analysis and interpretation of the data, statistical analysis, and critical revision of the manuscript for important intellectual

\section{REFERENCES}

1. Marson A, Housley WJ, Hafler DA. Genetic basis of autoimmunity. J Clin Invest (2015) 125(6):2234-41. doi:10.1172/JCI78086

2. Ramos PS, Shedlock AM, Langefeld CD. Genetics of autoimmune diseases: insights from population genetics. J Hum Genet (2015) 60(11):657-64. doi:10.1038/jhg.2015.94

3. Farh KK, Marson A, Zhu J, Kleinewietfeld M, Housley WJ, Beik S, et al. Genetic and epigenetic fine mapping of causal autoimmune disease variants. Nature (2015) 518(7539):337-43. doi:10.1038/nature13835

4. Cho JH, Feldman M. Heterogeneity of autoimmune diseases: pathophysiologic insights from genetics and implications for new therapies. Nat Med (2015) 21(7):730-8. doi:10.1038/nm.3897

5. Majka DS, Chang RW. Is preclinical autoimmunity benign? The case of cardiovascular disease. Rheum Dis Clin North Am (2014) 40(4):659-68. doi:10.1016/j.rdc.2014.07.006

6. Humphreys JH, Warner A, Chipping J, Marshall T, Lunt M, Symmons DP, et al. Mortality trends in patients with early rheumatoid arthritis over 20 content. FM, ZK, GW, PV, and NV had study supervision, contributed in study concept and design, acquisition of data, analysis and interpretation of data, critical revision of the manuscript for important intellectual content, obtained funding, and provided study supervision, administrative, and technical support. All listed authors gave final approval of the manuscript to be published and agreed to be accountable for all aspects of the work, ensuring that questions related to the accuracy or integrity of any part of the work are appropriately investigated and resolved.

\section{ACKNOWLEDGMENTS}

The authors are grateful to Giorgio Pistis for imputation of the CoLaus genetic data and Aaron McDaid for performing longevity lookup and imputation for their top SNP. The authors express their gratitude to all CoLaus study participants and the research nurses responsible for recruitment of participants, especially Nicole Bonvin. Special gratitude is expressed to Aliki Buhayer (Prism Scientific Sàrl) for medical writing support.

\section{FUNDING}

This work was supported by the Leenaards Foundation, the Faculty of Biology and Medicine of Lausanne, the Swiss National Science Foundation (grant numbers 3200B0-105993, 3200B0-118308, 33CSCO-122661, 33CS30-139468 and 33CS30148401, 310030-163335, 31003A-143914) and by the European Commission (FP7-INNOVATION I HEALTH-F2-2013-602114; Athero-B-Cell: Targeting and Exploiting B Cell Function for Treatment in Cardiovascular Disease). Funding sources had no involvement in the study design, in the collection, analysis, and interpretation of the data, in the writing of the report, or in the decision to submit the article for publication.

\section{SUPPLEMENTARY MATERIAL}

The Supplementary Material for this article can be found online at http://journal.frontiersin.org/article/10.3389/fimmu. 2017.00437/full\#supplementary-material.

years: results from the Norfolk Arthritis Register. Arthritis Care Res (Hoboken) (2014) 66(9):1296-301. doi:10.1002/acr.22296

7. Solow EB, Vongpatanasin W, Skaug B, Karp DR, Ayers C, de Lemos JA. Antinuclear antibodies are associated with all-cause mortality and cardiovascular outcomes in the general population. J Am Coll Cardiol (2015) 65(24):2669-70. doi:10.1016/j.jacc.2015.03.578

8. Vaarala O, Mänttäri M, Manninen V, Tenkanen L, Puurunen M, Aho K, et al. Anti-cardiolipin antibodies and risk of myocardial infarction in a prospective cohort of middle-aged men. Circulation (1995) 91(1):23-7. doi:10.1161/ 01.cir.91.1.23

9. Ajeganova S, Humphreys JH, Verheul MK, van Steenbergen HW, van Nies JAB, Hafström I, et al. Anticitrullinated protein antibodies and rheumatoid factor are associated with increased mortality but with different causes of death in patients with rheumatoid arthritis: a longitudinal study in three European cohorts. Ann Rheum Dis (2016) 75:1924-32. doi:10.1136/ annrheumdis-2015-208579

10. Ames PR, Matsuura E, Batuca JR, Ciampa A, Lopez LL, Ferrara F, et al. High-density lipoprotein inversely relates to its specific autoantibody favoring 
oxidation in thrombotic primary antiphospholipid syndrome. Lupus (2010) 19(6):711-6. doi:10.1177/0961203309357765

11. Batuca JR, Ames PR, Amaral M, Favas C, Isenberg DA, Delgado Alves J. Antiatherogenic and anti-inflammatory properties of high-density lipoprotein are affected by specific antibodies in systemic lupus erythematosus. Rheumatology (2009) 48(1):26-31. doi:10.1093/rheumatology/ken397

12. Batuca JR, Ames PR, Isenberg DA, Alves JD. Antibodies toward high-density lipoprotein components inhibit paraoxonase activity in patients with systemic lupus erythematosus. Ann N Y Acad Sci (2007) 1108:137-46. doi:10.1196/ annals. 1422.016

13. Delgado Alves J, Ames PR, Donohue S, Stanyer L, Nourooz-Zadeh J, Ravirajan $\mathrm{C}$, et al. Antibodies to high-density lipoprotein and beta2-glycoprotein I are inversely correlated with paraoxonase activity in systemic lupus erythematosus and primary antiphospholipid syndrome. Arthritis Rheum (2002) 46(10):2686-94. doi:10.1002/art.10542

14. Vuilleumier N, Bratt J, Alizadeh R, Jogestrand T, Hafstrom I, Frostegard J. Anti-apoA-1 IgG and oxidized LDL are raised in rheumatoid arthritis (RA): potential associations with cardiovascular disease and RA disease activity. Scand J Rheumatol (2010) 39(6):447-53. doi:10.3109/03009741003742755

15. Abe H, Tsuboi N, Suzuki S, Sakuraba H, Takanashi H, Tahara K, et al. Antiapolipoprotein A-I autoantibody: characterization of monoclonal autoantibodies from patients with systemic lupus erythematosus. J Rheumatol (2001) 28(5):990-5.

16. Ahmed MM, Elserougy EM, Al-Gazzar II, Fikry IM, Habib DF, Younes $\mathrm{KM}$, et al. Anti-apolipoprotein A-I antibodies and paraoxonase 1 activity in systemic lupus erythematosus. EXCLI J (2013) 12:719-32.

17. Srivastava R, Yu S, Parks BW, Black LL, Kabarowski JH. Autoimmunemediated reduction of high-density lipoprotein-cholesterol and paraoxonase 1 activity in systemic lupus erythematosus-prone gld mice. Arthritis Rheum (2011) 63(1):201-11. doi:10.1002/art.27764

18. Montecucco F, Braunersreuther V, Burger F, Lenglet S, Pelli G, Carbone F, et al. Anti-apoA-1 auto-antibodies increase mouse atherosclerotic plaque vulnerability, myocardial necrosis and mortality triggering TLR2 and TLR4. Thromb Haemost (2015) 114:410-22. doi:10.1160/th14-12-1039

19. Montecucco F, Vuilleumier N, Pagano S, Lenglet S, Bertolotto M, Braunersreuther $\mathrm{V}$, et al. Anti-apolipoprotein A-1 auto-antibodies are active mediators of atherosclerotic plaque vulnerability. Eur Heart J (2011) 32(4):412-21. doi:10.1093/eurheartj/ehq521

20. Pagano S, Carbone F, Burger F, Roth A, Bertolotto M, Pane B, et al. Antiapolipoprotein A-1 auto-antibodies as active modulators of atherothrombosis. Thromb Haemost (2016) 116(3):554-64. doi:10.1160/TH16-03-0229

21. Pagano S, Satta N, Werling D, Offord V, de Moerloose P, Charbonney E, et al. Anti-apolipoprotein A-1 IgG in patients with myocardial infarction promotes inflammation through TLR2/CD14 complex. J Intern Med (2012) 272(4):344-57. doi:10.1111/j.1365-2796.2012.02530.x

22. Vuilleumier N, Rossier MF, Pagano S, Python M, Charbonney E, Nkoulou R, et al. Anti-apolipoprotein A-1 IgG as an independent cardiovascular prognostic marker affecting basal heart rate in myocardial infarction. Eur Heart $J$ (2010) 31(7):815-23. doi:10.1093/eurheartj/ehq055

23. de Seny D, Cobraiville G, Charlier E, Neuville S, Lutteri L, Le Goff C, et al. Apolipoprotein-A1 as a damage-associated molecular patterns protein in osteoarthritis: ex vivo and in vitro pro-inflammatory properties. PLoS One (2015) 10(4):e0122904. doi:10.1371/journal.pone.0122904

24. Mannic T, Satta N, Pagano S, Virzi J, Python M, Montecucco F, et al. CD14 as a potential receptor and key regulator of anti-apolipoproteina-1 IgGmediated positive chronotropic effect on cardiac cells. Atherosclerosis (2015) 241(1):e6-7. doi:10.1016/j.atherosclerosis.2015.04.040

25. Antiochos P, Marques-Vidal P, Virzi J, Pagano S, Satta N, Bastardot F, et al. Association between anti-apolipoprotein A-1 antibodies and cardiovascular disease in the general population. Results from the CoLaus study. Thromb Haemost (2016) 116(4):764-71. doi:10.1160/TH16-03-0248

26. Chistiakov DA, Orekhov AN, Bobryshev YV. ApoA1 and ApoA1-specific self-antibodies in cardiovascular disease. Lab Invest (2016) 96(7):708-18. doi:10.1038/labinvest.2016.56

27. Batuca JR, Amaral MC, Favas C, Paula FS, Ames PR, Papoila AL, et al. Extended-release niacin increases anti-apolipoprotein A-I antibodies that block the antioxidant effect of high-density lipoprotein-cholesterol: the EXPLORE clinical trial. Br JClin Pharmacol (2016). doi:10.1111/ bcp. 13198
28. Radwan MM, El-Lebedy D, Fouda R, Elsorougy E. Anti-apolipoprotein A-1 antibodies and carotid intima-media thickness in Egyptian women with systemic lupus erythematosus. Clin Rheumatol (2014) 33(4):493-8. doi:10.1007/ s10067-013-2399-8

29. Armstrong DL, Zidovetzki R, Alarcon-Riquelme ME, Tsao BP, Criswell LA, Kimberly RP, et al. GWAS identifies novel SLE susceptibility genes and explains the association of the HLA region. Genes Immun (2014) 15(6):347-54. doi:10.1038/gene.2014.23

30. Stahl EA, Raychaudhuri S, Remmers EF, Xie G, Eyre S, Thomson BP, et al. Genome-wide association study meta-analysis identifies seven new rheumatoid arthritis risk loci. Nat Genet (2010) 42(6):508-14. doi:10.1038/ ng.582

31. Plagnol V, Howson JMM, Smyth DJ, Walker N, Hafler JP, Wallace C, et al. Genome-wide association analysis of autoantibody positivity in type 1 diabetes cases. PLoS Genet (2011) 7(8):e1002216. doi:10.1371/journal.pgen. 1002216

32. Chung SA, Taylor KE, Graham RR, Nititham J, Lee AT, Ortmann WA, et al. Differential genetic associations for systemic lupus erythematosus based on anti-dsDNA autoantibody production. PLoS Genet (2011) 7(3):e1001323. doi:10.1371/journal.pgen.1001323

33. Wellcome Trust Case Control Consortium, Australo-Anglo-American Spondylitis Consortium (TASC), Burton PR, Clayton DG, Cardon LR, Craddock N, et al. Association scan of 14,500 nonsynonymous SNPs in four diseases identifies autoimmunity variants. Nat Genet (2007) 39(11):1329-37. doi:10.1038/ng.2007.17

34. Kurreeman F, Liao K, Chibnik L, Hickey B, Stahl E, Gainer V, et al. Genetic basis of autoantibody positive and negative rheumatoid arthritis risk in a multi-ethnic cohort derived from electronic health records. Am J Hum Genet (2011) 88(1):57-69. doi:10.1016/j.ajhg.2010.12.007

35. Firmann M, Mayor V, Vidal PM, Bochud M, Pecoud A, Hayoz D, et al. The CoLaus study: a population-based study to investigate the epidemiology and genetic determinants of cardiovascular risk factors and metabolic syndrome. BMC Cardiovasc Disord (2008) 8:6. doi:10.1186/1471-2261-8-6

36. Piepoli MF, Hoes AW, Agewall S, Albus C, Brotons C, Catapano AL, et al. 2016 European Guidelines on cardiovascular disease prevention in clinical practice: The Sixth Joint Task Force of the European Society of Cardiology and Other Societies on Cardiovascular Disease Prevention in Clinical Practice (constituted by representatives of 10 societies and by invited experts) developed with the special contribution of the European Association for Cardiovascular Prevention \& Rehabilitation (EACPR). Eur Heart J (2016) 37(29):2315-81. doi:10.1093/eurheartj/ehw106

37. Vuilleumier N, Bas S, Pagano S, Montecucco F, Guerne PA, Finckh A, et al. Anti-apolipoprotein A-1 IgG predicts major cardiovascular events in patients with rheumatoid arthritis. Arthritis Rheum (2010) 62(9):2640-50. doi:10.1002/art.27546

38. Rasheed H, Phipps-Green AJ, Topless R, Smith MD, Hill C, Lester S, et al. Replication of association of the apolipoprotein A1-C3-A4 gene cluster with the risk of gout. Rheumatology (2016) 55(8):1421-30. doi:10.1093/ rheumatology/kew057

39. Cornaby C, Gibbons L, Mayhew V, Sloan CS, Welling A, Poole BD. B cell epitope spreading: mechanisms and contribution to autoimmune diseases. Immunol Lett (2015) 163(1):56-68. doi:10.1016/j.imlet.2014.11.001

40. Metzger M-H, Heier M, Mäki M, Bravi E, Schneider A, Löwel H, et al. Mortality excess in individuals with elevated IgA anti-transglutaminase antibodies: the KORA/MONICA Augsburg Cohort Study 1989-1998. Eur J Epidemiol (2006) 21(5):359-65. doi:10.1007/s10654-006-9002-4

41. Endler G, Marsik C, Jilma B, Schickbauer T, Vormittag R, Wagner O, et al. Anti-cardiolipin antibodies and overall survival in a large cohort: preliminary report. Clin Chem (2006) 52(6):1040-4. doi:10.1373/clinchem.2005. 063925

42. GTExPortal. (2017). Available from: http://www.gtexportal.org/

43. Gibson AW, Li FJ, Wu J, Edberg JC, Su K, Cafardi J, et al. The FCRL3-169CT promoter single-nucleotide polymorphism, which is associated with systemic lupus erythematosus in a Japanese population, predicts expression of receptor protein on CD19+ B cells. Arthritis Rheum (2009) 60(11):3510-2. doi:10.1002/ art. 24915

44. Yang Y, Su X, Zhang K, Zhou R. The Fc receptor-like 3 gene polymorphisms and susceptibility to autoimmune diseases: an updated meta-analysis. Autoimmunity (2013) 46(8):547-58. doi:10.3109/08916934.2013.835804 
45. Kochi Y, Myouzen K, Yamada R, Suzuki A, Kurosaki T, Nakamura Y, et al. FCRL3, an autoimmune susceptibility gene, has inhibitory potential on B-cell receptor-mediated signaling. J Immunol (2009) 183(9):5502-10. doi:10.4049/ jimmunol.0901982

46. Swainson LA, Mold JE, Bajpai UD, McCune JM. Expression of the autoimmune susceptibility gene FcRL3 on human regulatory $\mathrm{T}$ cells is associated with dysfunction and high levels of PD-1. J Immunol (2010) 184(7):3639-47. doi:10.4049/jimmunol.0903943

47. Kochi Y, Yamada R, Suzuki A, Harley JB, Shirasawa S, Sawada T, et al. A functional variant in FCRL3, encoding Fc receptor-like 3, is associated with rheumatoid arthritis and several autoimmunities. Nat Genet (2005) 37(5):478-85. doi:10.1038/ng1540

48. Bajpai UD, Swainson LA, Mold JE, Graf JD, Imboden JB, McCune JM. A functional variant in FCRL3 is associated with higher Fc receptor-like 3 expression on T cell subsets and rheumatoid arthritis disease activity. Arthritis Rheum (2012) 64(8):2451-9. doi:10.1002/art.34457
49. Cotsapas C, Hafler DA. Immune-mediated disease genetics: the shared basis of pathogenesis. Trends Immunol (2013) 34(1):22-6. doi:10.1016/j.it.2012.09.001

50. Yan W, Song H, Jiang J, Xu W, Gong Z, Duan Q, et al. Characteristics of $\mathrm{B}$ cell-associated gene expression in patients with coronary artery disease. $\mathrm{Mol}$ Med Rep (2016) 13(5):4113-21. doi:10.3892/mmr.2016.5029

Conflict of Interest Statement: The authors declare that the research was conducted in the absence of any commercial or financial relationships that could be construed as a potential conflict of interest.

Copyright (c) 2017 Antiochos, Marques-Vidal, Virzi, Pagano, Satta, Hartley, Montecucco, Mach, Kutalik, Waeber, Vollenweider and Vuilleumier. This is an open-access article distributed under the terms of the Creative Commons Attribution License (CC BY). The use, distribution or reproduction in other forums is permitted, provided the original author(s) or licensor are credited and that the original publication in this journal is cited, in accordance with accepted academic practice. No use, distribution or reproduction is permitted which does not comply with these terms. 